\title{
Michel Lichtlé, Balzac, le texte et la loi
}

\section{Susi Pietri}

\section{OpenEdition}

\section{Journals}

\section{Edizione digitale}

URL: http://journals.openedition.org/studifrancesi/2204

DOI: $10.4000 /$ studifrancesi.2204

ISSN: 2421-5856

\section{Editore}

Rosenberg \& Sellier

\section{Edizione cartacea}

Data di pubblicazione: 1 aprile 2014

Paginazione: 163-164

ISSN: 0039-2944

\section{Notizia bibliografica digitale}

Susi Pietri, « Michel Lichtlé, Balzac, le texte et la loi », Studi Francesi [Online], 172 (LVIII | I) | 2014, online dal 01 avril 2014, consultato il 18 septembre 2020. URL : http://journals.openedition.org/ studifrancesi/2204; DOI : https://doi.org/10.4000/studifrancesi.2204

\section{Questo documento è stato generato automaticamente il 18 settembre 2020.}

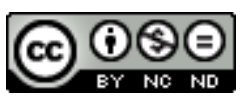

Studi Francesi è distribuita con Licenza Creative Commons Attribuzione - Non commerciale - Non opere derivate 4.0 Internazionale. 


\title{
Michel Lichtlé, Balzac, le texte et la loi
}

\author{
Susi Pietri
}

\section{NOTIZIA}

MiCHeL LichtLé, Balzac, le texte et la loi, études réunies par Sophie Vanden ABEELE, préface de Françoise méLonio, Paris, Presses de l’Université Paris-Sorbonne, 2012, pp. 518.

1 In un passo della sua celebre biografia di Balzac pubblicata nel 1859, Théophile Gautier, con ammirevole preveggenza critica, osserva che, se Stendhal confessava di leggere sempre tre o quattro pagine del Codice civile, prima di scrivere, «per trovare il tono giusto», Balzac, invece, ha saputo anche «scoprire nel Codice dei poemi e dei drammi» (Honoré de Balzac, Paris, Poulet-Malassis et De Broise, 1859, p. 68). Sulle orme di Gautier, Balzac, le texte et la loi ricostruisce magistralmente la pluralità dei percorsi attraverso $\mathrm{i}$ quali, in Balzac, la creazione narrativa esplora le problematiche giuridiche più urgenti $\mathrm{e}$ più complesse del tempo traducendosi in riflessione sul Diritto e in interrogazione critica della Legge. Il corpus esaminato include l'insieme dei testi balzachiani, senza omettere le cuvres de jeunesse né trascurare la formazione del giovane Balzac, studente alla Facoltà di Diritto di Parigi dal 1816 al 1819 (Balzac à l'école du droit, pp. 137-156). Secondo le dichiarazioni programmatiche di Michel Lichtlé (Balzac et le Code civil, pp. 157-173), non si tratta semplicemente di recensire l'abbondanza e la diversità dei processi, delle inchieste, delle consultazioni di uomini di legge, delle considerazioni sui codici civili e penali che pullulano nella Comédie humaine. Al di là dei romanzi direttamente collegati a tematiche giudiziarie, l'opera balzachiana è infatti permeata da un diffuso «discorso giuridico» che investe la rappresentazione del quotidiano, della vita intima, dell'esistenza ordinaria: nascite, eredità, matrimoni, ipoteche, acquisizioni di beni scatenano duelli drammatici e lotte mortali la cui arena è spesso lo studio dell'avvocato, del notaio o del giudice. Il Codice civile del 1804 fornisce all'invenzione romanzesca «una sorta di dizionario dei conflitti potenziali di cui è gravida la società moderna» (p. 176), un formidabile arsenale giuridico di armi che il romanzo balzachiano sa far detonare, innovando radicalmente le sue forme e i suoi intrecci narrativi. Il mondo immaginario de La Comédie humaine, nella prospettiva adottata da 
Lichtlé, è in questo senso un campo di battaglia sconvolto dal turbinare di passioni e interessi contrapposti che travolgono anche le istanze della legge. Sullo sfondo della dilagante idolatria del denaro e del successo, le figure e le istituzioni giuridiche dell'universo balzachiano mettono in scena il fallimento della possibilità di regolare l'antagonismo tra le aspirazioni dell'individuo e l'ordine sociale (Balzac et la notion de gouvernement moderne, pp. 355-396). Nell'esemplare conclusione di Le Colonel Chabert, il colore nero degli abiti indossati da preti, medici e avvocati figura la desolazione di "coloro che non possono più stimare gli uomini» per l'esperienza costante dei loro delitti, suggellando il «lutto universale» delle speranze umane (La Comédie humaine, edizione diretta da Pierre-Georges Castex, Paris, Gallimard, 1976-1981, vol. III, p. 373). E ancora nel segno del «lutto» si inscrivono le denunce balzachiane dell'impotenza della giustizia, la cui azione si arresta sulla soglia del «male morale» (Sur “L'Interdiction", pp. 205-220), dei «crimini e misfatti» impuniti della vita privata che sfuggono perversamente alla repressione e alla sanzione, costituendo così il territorio privilegiato per un'acuminata riflessione sui limiti stessi della legge (Le Colonel Chabert, roman judiciaire, pp. 175-204), insieme all'analisi della presenza onnipervasiva di spietati «codici» sociali e mondani, contro i quali il pur ammirato Codice civile napoleonico rivela la sua rovinosa inefficacia (Crimes et châtiments de la vie privée dans "Le Lys dans la vallée", pp. 317-329).

2 Nell'indagine di Licthlé, lo spazio dell'utopia balzachiana di una giustizia improntata alla «riparazione» e al «perdono» (Balzac et la justice de paix, pp. 221-236) o di un mistico «altrove» delle leggi umane, sottratto alla loro manchevole contingenza ma consegnato al tragico scacco dell'alienazione (L'aventure de Louis Lambert, pp. 417-448), cede dunque il passo al disincanto, con la lucida consapevolezza della dimensione profondamente politica imbricata nella teoria e nella prassi del Diritto civile e penale (Du roman et de la société en France à l'époque romantique: Balzac devant la peine de mort, pp. 237-263), non già manifestazione di un ordine razionale ma espressione delle coalizioni di interessi economici e sociali coagulatisi nei decenni della Restaurazione e della rivoluzione liberale del 1830. Anche nel deserto delle «illusioni perdute», tuttavia, mentre si fa strada l'infernale visione di un universo sociale ormai in preda alla potenza sfrenata del «genio del male» (La Comédie humaine, edizione citata, vol. IX, p. 1079), la riflessione critica di Balzac continua a esercitarsi tra tensioni, proposte di riforma, provocazioni paradossali, contraddizioni e ripensamenti successivi, interrogando ostinatamente gli splendori e le miserie della giustizia umana (Images balzaciennes de la justice, pp. 331-351) nelle mises en scène narrative che, allo stesso tempo, aprono il romanzo a impensati, inediti campi della rappresentazione.

3 Questa «eterna genesi» (come sottolinea l'introduzione di Françoise MÉLoNIO, pp. 7-13) del pensiero di Balzac, sempre restio a fissarsi in articolazioni sistematiche e univoche malgrado l'ossessiva volontà di coerenza di cui si nutre, fin dalle origini, il progetto della Comédie humaine, prende forma e si riflette nella genesi infinita della stessa scrittura balzachiana. Un'ampia sezione del volume ripercorre analiticamente fasi ed aspetti cruciali dell'interminabile edificazione del Monumento narrativo di Balzac, riesaminando le condizioni specifiche e materiali di produzione dei suoi testi, dal tormentato rapporto con gli editori alle aspre battaglie contro le pubblicazioni abusive o le edizioni pirata di opere sottratte fraudolentemente ai diritti d'autore (Balzac et la «Revue étrangère», pp. 119-134), dalle sperimentazioni del roman-feuilleton (L'insertion du texte balzacien dans «Le Siècle», pp. 73-118) alla gestione sempre più complessa, nel corso 
del tempo, delle campagne di revisione e riscrittura che investono tutti i romanzi e i racconti riuniti nella Comédie humaine. La densissima, accurata ricognizione condotta da Michel Lichtlé permette di ridisegnare la ricchissima, articolata mappa dei principali modi, tipologie e procedure del laboratorio creativo di Balzac, con le strategie compositive corrispondenti (La gestion balzacienne des épreuves, pp. 49-72). Le addizioni progressive e i rifacimenti integrali, i reimpieghi di scritti pre-pubblicati in rivista, gli sviluppi imprevisti in corso d'opera, la ristrutturazione permanente del «ritorno sistematico dei personaggi», le riedizioni ampiamente rimaneggiate, l'accumulo di bozze di stampa in cui il testo trova lentamente, in fieri, il suo equilibrio e la sua massa, concorrono a moltiplicare tutti gli stadi intermedi della rielaborazione genetica, quasi a voler abolire ogni tradizionale frontiera tra la sfera dei manoscritti e quella delle opere pubblicate (Pour Balzac, pp. 39 ss.). Ovvero, come non manca di sottolineare Lichtlé, nella costruzione globale de La Comédie humaine le stesse edizioni a stampa sembrano trasformarsi in "stati provvisori di un cantiere indefinitamente aperto» (p. 49). Si definisce, così, la vera e propria «legge» del Grande Testo balzachiano nel corso del suo farsi, con il costante ritorno della scrittura su se stessa che ha esteso a dismisura, insieme ai confini del processo genetico, anche i possibili della forma-romanzo. 